\title{
Prognostic value of minimal excitability of facial nerve in Bell's palsy
}

\author{
SARALA DEVI, Y. CHALLENOR, N. DUARTE \\ A N D R. E. L O VELACE \\ From the Neurological Institute of New York, and Harlem Hospital Medical Center, Department of \\ Neurology, College of Physicians and Surgeons, Columbia University, and the H. Houston Merrit \\ Clinical Research Center for Muscular Dystrophy and Related Diseases, New York, USA
}

SUMMARY Nerve excitability is useful for prognosis in Bell's palsy. Minimal excitability values (MEV) were obtained by stimulating the facial nerve and recording the effective current (mA) required to evoke a minimal visible contraction of frontalis, orbicularis oculi, orbicularis oris, and mentalis muscles respectively. Serial MEVs were performed on 100 patients with facial palsy, of whom 87 were followed for six months or to complete recovery; 61 patients were treated with steroids of whom 57 had good recovery. Serial MEVs were not only useful for prognosis, but also helpful in regulating the dosage of prednisone.

Facial nerve excitability tests (Gilliatt and Taylor, 1959) are used to determine the course of facial nerve dysfunction, and to select patients for surgical decompression. Alford (1967) stated that nerve excitability studies are useful 72 hours after the onset of paralysis. Campbell et al. (1962), Laumans (1965), and Leclaire et al. (1975) correlated nerve excitability tests with the rate of recovery. Since prednisone is widely used to treat Bell's palsy, it is important to determine whether serial nerve excitability tests can be used to modify dosage.

\section{Patients and methods}

One hundred patients were seen in the three years from 1973 to 1976. All had facial paralysis that was maximal in one or two days. The history or examination indicated that the palsy was complete or nearly complete in all cases. The usual diagnostic tests as suggested by the anatomical and diagnostic reviews of Paine (1957) and Alford et al. (1974), were performed in order to localise the

Supported by a Center Grant from the Muscular Dystrophy Association. Presented at the 23rd Annual Meeting of the American Association of Electromyography and Electrodiagnosis, November 1976. Dr N. Duarte was a Clinical Fellow of the Muscular Dystrophy Association and Dr Y. Challenor is director of the electromyographic laboratories at Harlem Hospital.

Address for reprint requests: Dr S. Devi, The Neurological Institute, 710 West 168th Street, New York, New York 10032, USA.

Accepted 30 January 1978 lesion. Facial nerve excitability was tested by applying an electrical stimulus consisting of a square wave pulse of $0.1 \mathrm{~ms}$ duration repeated once per second, delivered by TE3/TE4 Muscle Stimulator 6. On stimulation of the branches of the facial nerve immediately anterior to the tragus of the ear, the minimal effective current intensity required to evoke a visible contraction was noted in milliamperes and expressed as minimal excitability values (MEV). The minimal excitability values were obtained for frontalis, orbicularis oculi, orbicularis oris, and mentalis muscles. For comparison MEVs were also determined on the contralateral side. Differing durations of stimuli for minimal excitability to cover points on the strength duration curve were tried. A duration of $0.03 \mathrm{~ms}$ was consistently too low for abnormal values, and in only one case did durations of 0.3 and $1 \mathrm{~ms}$ give a response where lower values had failed.

In our laboratory, the normal range for MEVs is 2 to $10 \mathrm{~mA}$ as determined bilaterally in 15 normal subjects aged 20 to 50 years. This is consistent with values reported in the literature (Laumans, 1965). Usually, these values are similar to those found on the unaffected side in 72 of our patients. Values over 10 are regarded as abnormal. Normally, there is a difference of no more than $2 \mathrm{~mA}$ between the MEVs on the two sides. Differences greater than $5 \mathrm{~mA}$ are said to imply a poor prognosis. Motor latency of $4 \mathrm{~ms}$ or less (Gilliatt 
and Taylor, 1959; Taverner, 1965) and an evoked potential with an amplitude of $1.0 \mathrm{mV}$ or greater are regarded as normal.

The patients ranged in age from 1 to 77 years (15 under 15 years), and at onset the palsy was usually complete or near complete. In 67 patients the first study was done before the eighth day, and in 11 of these as early as the second day. Another 16 patients were studied from nine to 14 days. Relatively few patients had first MEVs after two weeks. The patients seen by the sixth day after onset received only MEV measurements, and these were repeated twice a week. At this stage at least one-third of the patients required adjustment of the dosage of prednisone. Motor latencies were estimated after the seventh day, and needle electromyography performed to determine the extent of denervation changes approximately one week later. Motor latencies of the facial nerve to frontalis, orbicularis oculi, orbicularis oris, and mentalis muscles were measured on the affected side, and compared with those of the clinically unaffected side. In children or in adults with relatively normal MEVs, and also in patients with clear clinical improvement, electromyography was not performed.

Seventy-eight patients were treated with steroids, usually prednisone, but one patient received dexamethasone. Our standard regimen is to start with $60 \mathrm{mg}$ of prednisone per day for four days as recommended by Adour et al. (1972), followed by tapering of the dose over the next two to four weeks. This was regarded as adequate therapy. It was modified according to the MEVs in a few cases where the dosage was increased or a higher dosage was maintained for a longer period. In children a dose of $2 \mathrm{mg} / \mathrm{kg}$ body weight was given and similarly tapered. In 26 patients inadequate or no steroids were given, usually due to noncompliance with therapy. A contraindication was present in only five of these patients. Diabetes mellitus was not considered to be a contraindication; however, in patients with moderately severe diabetes, a lower dose of prednisone was given.

\section{Results}

In 25 patients, the initial MEVs were within the normal range, with less than $2 \mathrm{~mA}$ difference between the two sides. A difference of 3 to $5 \mathrm{~mA}$ was seen at one or more muscles in 26 patients, and a difference of 6 to $10 \mathrm{~mA}$ in another 26 patients. In 23 patients, no response was obtained, or a difference of greater than $10 \mathrm{~mA}$ was seen. Minimal excitability values were increased bilaterally in 28 patients (Table 1). Of these, only four
Table 1 Results of MEV study

\begin{tabular}{ll}
$M E V$ difference & \\
$(m A)$ & Number of cases \\
\hline$<2$ & 25 \\
$3-5$ & 26 \\
$6-10$ & 26 \\
$>10$ or no response & 23 \\
Bilaterally increased & 28 \\
\hline
\end{tabular}

patients had clinical evidence of bilateral Bell's palsy.

Patients with normal MEVs or with a difference between right and left of less than $5 \mathrm{~mA}$ also had normal distal motor latencies, but the evoked potential was usually of lower amplitude than normal. These patients showed little or no denervation changes. Patients with increased MEVs usually showed prolonged distal motor latencies, again with reduced amplitude of the evoked potentials. Acute denervation changes were also greater in these patients, roughly proportional to the increased MEVs. The patients in whom no MEVs could be recorded, also showed severe acute denervation changes, with no motor unit potentials. In these patients, the distal motor latencies were also unrecordable.

Patients in whom the MEVs were normal or slightly increased (difference of 3 to $5 \mathrm{~mA}$ ) usually showed complete recovery. Patients with significantly increased MEVs (greater than $5 \mathrm{~mA}$ difference) did poorly, unless the MEV returned to normal or clearly improved within one week. Patients with continuing complete paralysis in whom no MEV could be recorded, showed minimal or no recovery. Eighty-seven patients were followed until there was complete or good partial recovery or up to six months. Fifty-three patients $(60.9 \%)$ showed complete recovery, 23 patients $(26.4 \%)$ had good partial recovery, and 11 patients $(12.7 \%)$ showed minimal or no recovery.

Of those 87 patients followed, 61 received steroid therapy, 26 received inadequate or no therapy. In 61 patients treated with steroids 36 had MEVs with less than $5 \mathrm{~mA}$ difference. Of these, 31 recovered completely, three partially, and two poorly. Among the 14 patients who had a difference of 6 to $10 \mathrm{~mA}, 10$ recovered completely and four partially. Eleven patients had a difference of greater than $10 \mathrm{~mA}$ or no response; five of them recovered completely, four partially, and two poorly (Table 2 ).

Twenty-six patients received inadequate or no steroid therapy. Twelve of these patients had less than $5 \mathrm{~mA}$ difference; six recovered completely, four partially, and two poorly. Six patients had an MEV difference of 6 to $10 \mathrm{~mA}$; three of them re- 
Table 2 Adequate steroid therapy-61 patients

\begin{tabular}{lccc}
\hline$M E V(m A$ difference $)$ & $<5$ & $6-10$ & $\begin{array}{l}>10 \text { or no } \\
\text { response }\end{array}$ \\
\hline Total number of patients & 36 & 14 & 11 \\
\hline Complete recovery & 31 & 10 & 5 \\
Partial recovery & 3 & 4 & 4 \\
Poor or no recovery & 2 & 0 & 2 \\
\hline
\end{tabular}

covered completely and three partially. Eight patients showed no response or greater than 10 $\mathrm{mA}$ difference; only one recovered completely after decompression, two had good partial recovery, and five had poor or no recovery (Table 3 ).

Table 3 No or inadequate steroid therapy-26 patients

\begin{tabular}{llll}
\hline$M E V(m A$ difference $)$ & $<5$ & $6-10$ & $\begin{array}{l}>10 \text { or } \\
\text { no response }\end{array}$ \\
\hline Total number of patients & 12 & 6 & 8 \\
\hline Complete recovery & 6 & 3 & 1 \\
Partial recovery & 4 & 3 & 2 \\
Poor or no recovery & 2 & 0 & 5 \\
\hline
\end{tabular}

In summary, of the 61 patients treated with adequate steroids, $46(75 \%)$ showed complete recovery. Eleven $(18 \%)$ recovered partially, four $(7 \%)$ poorly. Of the 26 with no or inadequate therapy, $10(38 \%)$ recovered completely, nine $(35 \%)$ partially, and seven $(27 \%)$ poorly (Table 4$)$.

Table 4 Results of steroid therapy

\begin{tabular}{lllll}
\hline Therapy & Total & $\begin{array}{l}\text { Complete } \\
\text { recovery }\end{array}$ & $\begin{array}{l}\text { Partial } \\
\text { recovery }\end{array}$ & $\begin{array}{l}\text { Poor or } \\
\text { no recovery }\end{array}$ \\
\hline $\begin{array}{l}\text { Steroids } \\
\text { None or } \\
\text { inadequate }\end{array}$ & 61 & $46(75.0 \%)$ & $11(18.0 \%)$ & $4(7 \%)$ \\
\hline
\end{tabular}

In approximately one-third of these patients, prednisone dosage was modified according to the MEVs. In one child aged 14 years, upon noticing the apparent increase in MEV which was also associated with clinical deterioration, a second course of prednisone therapy was instituted which resulted in significant improvement (Table 5). More commonly, a higher dose of prednisone was maintained for longer periods until a significant improvement in the MEVs was noticed. Most patients are now managed in this way.

\section{Dissussion}

Sir Charles Bell, in his book The Nervous System of the Human Body (1844), described cases with unilateral facial palsy, including cases secondary
Table 5 MEVs of patient aged 14 years-prednisone was started on fifth day

\begin{tabular}{|c|c|c|c|c|c|}
\hline \multirow{2}{*}{$\begin{array}{l}\text { Number of } \\
\text { days after } \\
\text { onset of } \\
\text { therapy }\end{array}$} & \multirow{2}{*}{$\begin{array}{l}\text { Dosage of } \\
\text { prednisone } \\
\text { (mg/day) }\end{array}$} & \multirow[b]{2}{*}{ Frontalis } & \multicolumn{3}{|l|}{$M E V(m A)$} \\
\hline & & & $\begin{array}{l}\text { Orbicularis } \\
\text { oculi }\end{array}$ & $\begin{array}{l}\text { Orbicularis } \\
\text { oris }\end{array}$ & Mentalis \\
\hline 4 & 40 & 7 & 13 & 8 & 7 \\
\hline 10 & 10 & 5 & 9 & 9 & 5 \\
\hline 18 & - & 4.5 & 10 & 9 & 9 \\
\hline 31 & $0 / 60$ & 10 & 20 & 18 & 10 \\
\hline 36 & 40 & 7 & 15 & 15 & 10 \\
\hline 42 & 20 & 5 & 15 & 16 & 10 \\
\hline 46 & - & 5 & 15 & 9 & 6 \\
\hline
\end{tabular}

to tumour, compression trauma, and chronic otitis media. However, the patients described in our study had facial paralysis of sudden onset with no immediate cause. The aetiology in most cases of unilateral facial palsy (Bell's palsy) remains obscure, although a viral cause is postulated. The role of herpes zoster virus in the aetiology of facial palsy is well-known (Hunt, 1907; Aitken and Brain, 1933). Since then, several other viruses have been implicated in the aetiology of Bell's palsy (Saunders, 1963; Grose et al., 1973; Pollack et al., 1975). Recently, Adour et al. (1975) suggested that Bell's palsy may be caused by reactivation of herpes simplex virus.

Prednisone is now being widely used to treat Bell's palsy (Adour et al., 1972). Minimal excitability values have been helpful not only in determining the prognosis of Bell's palsy (Leclaire et al., 1975) but in modifying prednisone therapy. Patients with normal MEVs or with less than $5 \mathrm{~mA}$ difference between the two sides, usually recovered completely. Those with a difference of more than $5 \mathrm{~mA}$, usually recovered incompletely, unless the MEVs returned to normal or clearly improved within the first week. When MEVs were persistently abnormal, prednisone therapy was modified. The prognosis was poorest in patients with complete paralysis and who showed no response to stimulation. Recovery was also prolonged when MEVs were increased for longer than one week. Twenty-eight patients had bilaterally increased MEVs, four with bilateral paralysis. However, a higher incidence of bilateral pathology has been reported (Safman, 1971).

Children and diabetic patients showed slower recovery than normal adults, and often the prednisone had to be adjusted according to the MEV (Table 5). In discussion of Lauman's study (1965), Groves mentioned that, in his experience, quite frequently there was sudden worsening of nerve excitability one or two days before spontaneous recovery of voluntary movement. On careful review, we found no evidence of this phenomenon in 
our study, and indeed most patients exhibiting a deterioration in nerve excitability had clinical worsening. Adour and Wingerd (1974) also found poor outcome in patients with diabetes mellitus. In patients with severe palsy where a difference in MEV of greater than $5 \mathrm{~mA}$ was recorded, it is our clinical impression that prednisone shortened the time of recovery. However, in our unselected cases, comparison of treated and untreated patients indicated that steroid therapy was effective to a degree which was highly significant statistically $\left(5\right.$ per 1000 significance level; $x^{2}=$ 11.51; df =2).

Our partial recovery state is essentially a good partial recovery, and in this study we found that $93 \%(75+18)$ of steroid-treated patients reached this level and only $73 \%(38+35)$ of essentially untreated patients did so. This figure for steroidtreated patients is comparable with the therapeutic results of Adour and Wingerd (1974).

We wish to thank Dr L. P. Rowland for helpful criticisms and comments, our colleagues for referring appropriate patients to us, and Dr Hans Luders and $\mathrm{Mr} \mathrm{L}$. Zablow for assistance in statistical analysis.

\section{References}

Adour, K. K., Wingerd, J., Bell, D. N., Manning, J. J., and Hurley, J. P. (1972). Prednisone treatment for idiopathic facial paralysis (Bell's palsy). New England Journal of Medicine, 287, 1268-1272.

Adour, K. K., and Wingerd, J. (1974). Idiopathic facial paralysis (Bell's palsy): factors affecting severity and outcome in 446 patients. Neurology (Minneapolis), 24, 1112-1116.

Adour, K. K., Bell, D. N., and Hilsinger, R. L. (1975). Herpes simplex virus in idiopathic facial paralysis (Bell's palsy). Journal of the American Medical Association, 233, 527-530.
Aitken, R. S., and Brain, R. T. (1933). Facial palsy and infection with Zoster virus. Lancet, 1, 19-22.

Alford, B. R. (1967). Electrodiagnostic studies in facial paralysis. Archives of Otolaryngology, 85, 259-264.

Alford, B. R., Jerger, J. F., Coats, A. C., Peterson, C. R., and Weber, S. C. (1974). Diagnostic tests of facial nerve function. Otolaryngologic Clinics of North America, 7, 331-342.

Bell, Sir Charles. (1844). The Nervous System of the Human Body. Third edition. Renshaw: London.

Campbell, E. D. R., Hickey, R. P., Nixon, K. H., and Richardson, A. T. (1962). Value of nerve excitability measurements in prognosis of facial palsy. British Medical Journal, 2, 7-10.

Gilliatt, R. W., and Taylor, J. C. (1959). Electrical changes following section of the facial nerve. Proceedings of the Royal Society of Medicine, 52, 1080-1083.

Grose, C., Feorino, P. M., Dye, L. A., and Rand, J. (1973). Bell's palsy and infectious mononucleosis. Lancet, 2, 231-232.

Hunt, J. R. (1907). On herpetic inflammation of the geniculate ganglion. A new syndrome and its complications. Journal of Nervous and Mental Diseases, 34, 73-96.

Laumans, E. P. J. (1965). Nerve excitability tests in facial paralysis. Archives of Otolaryngology, 81, 478-488.

Leclaire, R., Tremblay, L., and Dupuis, M. (1975). Prognostic value of nerve excitability test in Bell's palsy. Canadian Journal of Otolaryngology, 4, 352357.

Paine, R. S. (1957). Facial paralysis in children (review article). Pediatrics, 19, 303-316.

Pollack, M. A., Grose, C., and Friend, H. (1975). Measles associated with Bell's palsy. American Journal of Diseases of Children, 129, 747.

Safman, B. L. (1971). Bilateral pathology in Bell's palsy. Archives of Otolaryngology, 93, 55-57.

Saunders, W. H. (1963). Viral infections and cranial nerve paralysis. Archives of Otolaryngology, 78, 85-90.

Taverner, D. (1965). Electrodiagnosis in facial palsy. Archives of Otolaryngology, 81, 470-477. 